\title{
Socioeconomic outcome of subjects experiencing asthma symptoms at work
}

\author{
A. Larbanois*, J. Jamart", J-P. Delwiche*, O. Vandenplas*,
}

Socioeconomic outcome of subjects experiencing asthma symptoms at work. A. Larbanois, J. Jamart, J-P. Delwiche, O. Vandenplas. C) ERS Journals Ltd 2002. ABSTRACT: The aim of this study was to investigate the socioeconomic outcomes of subjects who experienced work-related asthma symptoms in the absence of demonstrable occupational asthma (OA) and to compare these outcomes with those found in subjects with documented $\mathrm{OA}$.

Subjects $(n=157)$ who were being investigated for work-related asthma, were surveyed. Of these 86 had $\mathrm{OA}$, ascertained by a positive specific inhalation challenge (SIC), and 71 subjects had a negative SIC response. After a median interval of 43 months (range 12-85 months), the subjects were interviewed to collect information on employment status, income changes, and asthma-related work disability.

Rates of work disruption and income loss at follow-up were similar in subjects with negative SIC (46\% and 59\%, respectively) and in those with OA $(38 \%$ and $62 \%)$. The median loss as a percentage of initial income was $23 \%$ in subjects with negative SIC and $\mathbf{2 2} \%$ in subjects with OA. Asthma-related work disability, defined as any job change or work loss due to asthma, was slightly more common in subjects with $\mathrm{OA}(72 \%)$ than in those with negative SIC (54\%).

This study shows that, even in the absence of demonstrable occupational asthma, work-related asthma symptoms are associated with considerable socioeconomic consequences.

Eur Respir J 2002; 19: 1107-1113.
*Service de Pneumologie, ${ }^{\#}$ Centre de Biostatistique et de Documentation Médicale, Cliniques Universitaires de Mont-Godinne, Université Catholique de Louvain, Yvoir and "Fonds des Maladies Professionnelles, Brussels, Belgium.

Correspondence: O. Vandenplas, Service de Pneumologie, Cliniques Universitaires de Mont-Godinne, 5530 Yvoir, Belgium.

Fax: 3281423352

E-mail: olivier.vandenplas@

pneu.ucl.ac.be

Keywords: Asthma, bronchoprovocation test, disability, economic consequences, occupational disease

Received: August 142001

Accepted after revision February 2 2002

This study was supported by the Services Fédéraux des Affaires Scientifiques, Techniques et Culturelles, Programme d'appui scientifique à la protection des travailleurs grant SSTC $\mathrm{PS} / 10 / 44$.
Epidemiological surveys have highlighted the importance of workplace exposure in initiating or triggering asthma symptoms [1, 2]. Work-related asthma symptoms can result either from immunological occupational asthma (OA) with a latency period or from concurrent or pre-existing asthma worsened by irritants or physical stimuli in the workplace [3]. A substantial proportion of subjects experiencing worsening of asthma symptoms at work have failed to demonstrate objective evidence of work-related changes in physiological indices of asthma [2, 4]. However, distinguishing between subjects with OA and those who are symptomatically worse at work is important for both medical and medicolegal reasons [5]. Immunological OA is characterized by the development of specific bronchial hyperreactivity to occupational agents, although the precise mechanisms involved in OA caused by low molecular weight chemicals have not yet been identified precisely [3]. In subjects with OA, repeated exposure to the causative agent is associated with an increase in airway inflammation and in nonspecific bronchial hyperresponsiveness $[6,7]$, which can lead to progressive worsening of asthma. Therefore, the treatment for OA is to remove the affected worker from exposure to the causative agent. Several studies have explored the economic consequences of OA [8-14]. By contrast, little information is available on the outcome of subjects who are symptomatically worse at work [9].

The aim of this study was to characterize the socioeconomic outcome of subjects with work-related asthma symptoms in the absence of demonstrable OA. Therefore, a group of subjects who experienced work-aggravated asthma symptoms, but failed to develop a positive response to specific inhalation challenge (SIC) with occupational agents, were investigated. The socioeconomic outcomes of these subjects were compared with those in subjects with OA.

\section{Methods}

\section{Subjects}

Subjects ( $\mathrm{n}=186)$ who were referred to the authors' centre, between the years 1994-1999, for investigation 
of asthma symptoms temporally related to workplace exposure were surveyed. Based on the results of SIC, the subjects were categorized into two groups: 1) those who demonstrated positive SIC were regarded as having OA and 2) those who failed to develop a bronchial response during SIC were categorized as experiencing work-aggravated asthma symptoms without objective evidence of OA.

A total of 201 subjects had been investigated for work-related asthma symptoms during this period. Six subjects were excluded from the cohort because their clinical history was consistent with irritant-induced asthma. In these subjects, the onset of asthma symptoms clearly occurred within hours after unusually high level exposure to irritants at work. Three of these six subjects underwent SIC in order to exclude sensitization to the causative agent and these SICs were negative. Nine other subjects were not enrolled in the follow-up study because the results of SIC could not be interpreted accurately: three subjects could not be challenged with the agent or process that was suspected of provoking asthma symptoms at work, and six subjects showed nonreproducible changes in forced expiratory volume in one second (FEV1) during SIC.

\section{Study design}

Initial assessment at the time of the diagnostic investigation included a detailed occupational and medical questionnaire, skin-prick testing with a battery of common inhalant allergens and with occupational agents when relevant extracts were available, measurement of spirometry and nonspecific bronchial hyperresponsiveness to histamine and SIC. The subjects' medical records were analysed by a research assistant in order to retrieve information on sociodemographical, occupational, and medical characteristics. Information on asthma symptoms and use of medications were collected either during the last month before SIC, if the subject was still exposed to the offending agent(s), or during the last month at work, if the subject had been removed from exposure.

Eligible subjects were sent an invitation to participate, detailed information on the study protocol, and an informed consent form. The invitation explained that information obtained through the study would not be used for medicolegal purposes. The protocol of the study was approved by the Ethics Committee of Mont-Godinne University Hospital. The subjects were then contacted by telephone and given a structured questionnaire to obtain the following information: job changes related to asthma symptoms, current working status, current exposure to agent(s) causing asthma symptoms, perceived magnitude of income changes, actual income during the last year at work prior to initial assessment, income at the time of follow-up and compensation status.

\section{Lung function assessment}

At the time of diagnostic evaluation, FEV1 and forced vital capacity (FVC) were measured according to the recommendations of the American Thoracic Society [15] using a pneumotachograph instrument (Medisoft, Dinant, Belgium). Predicted values were those of the European Coal and Steel Community [16]. Nonspecific bronchial hyperresponsiveness to histamine was assessed using the method described by Cockcroft et al. [17]. The level of nonspecific bronchial hyperresponsiveness was expressed as the provcocation concentration of histamine causing a $20 \%$ fall in FEV1 (PC20). PC20 values $<16 \mathrm{mg} \cdot \mathrm{mL}^{-1}$ were considered as reflecting significant bronchial hyperresponsiveness.

\section{Specific inhalation challenges}

SICs were performed as previously described [18]. On the first day, the subjects were exposed to a control substance to ensure that there was no significant fluctuation of the FEV1. On subsequent days, the subjects were challenged with occupational agent(s) suspected of causing work-related asthma based on clinical history and inspection of the workplace by hygienists from the Workers' Compensation Board (WCB). Exposure to occupational agents was produced in a realistic way, by reproducing the physical features (e.g. temperature, dust, aerosol, vapour or fume) encountered at the workplace. The duration of exposure was gradually increased to a total of $2 \mathrm{~h}$ on the first challenge day. In the absence of significant change in FEV1, challenge exposure was repeated for $2-3 \mathrm{~h}$ on at least one subsequent day. Baseline histamine PC20 value was determined at the end of the control day and reassessed 6-8 h after the end of each challenge exposure in the absence of a significant change in airway calibre. A SIC result was considered positive if there was: 1) a sustained fall in FEV1 of $\geqslant 20 \%$ or 2 ) a significant ( $>3$-fold) decrease in postchallenge histamine $\mathrm{PC} 20$ as compared with the baseline value [18].

\section{Analysis of results}

Asthma-related work disability was defined as any self-reported job change or work loss due to asthma [19]. The severity of asthma was graded using a score proposed by BLANC et al. [20] for assessing work disability among adult asthmatics. This score (ranging $0-28$ ) is based on hospital admissions, frequency of asthma symptoms, and use of asthma medications. Atopy was defined by the presence of a positive skin test to at least one common allergen.

Data are presented as the median with 25 th and 75 th percentiles. Comparison between subjects with $\mathrm{OA}$ and those with a negative SIC response was made using the Chi-squared test, Fisher exact test or Wilcoxon rank-sum test as appropriate. The Spearman coefficient was used to assess correlations between variables. Multivariate logistic regression analysis was carried out to explore the determinants of unemployment at follow-up. This analysis included the following independent variables: positive or negative SIC, asthma-severity score, the logarithm of 
histamine $\mathrm{PC} 20$ value at initial examination, time elapsed since onset of work-related symptoms, age, level of education and size of the company. A p-value $<0.05$ was considered significant.

\section{Results}

\section{Nonparticipants}

At the time of the follow-up assessment, five subjects (including one subject with OA) had died from nonrespiratory disease. Of 181 subjects, 157 $(87 \%)$ agreed to participate, while 24 subjects either could not be traced or declined to participate in the study $(n=7)$. Nonparticipants included a higher proportion of current smokers (10 of 24 versus 21 of $157, \mathrm{p}=0.003)$ and of subjects referred by the WCB (22 of 24 versus 97 of $157, p=0.004$ ) than participants. The asthma-severity score at initial assessment was slightly lower in nonparticipants (median score 6, 25-75th percentile 4-8) than in participants (median score 7, $25-75$ th percentile $5-9, \mathrm{p}=0.037$ ).

\section{Baseline characteristics of participants}

Of the 157 participants, $86(55 \%)$ subjects showed a positive SIC response and were diagnosed as having OA, whereas 71 subjects demonstrated a negative SIC. Low molecular weight agents were more frequently involved in subjects with negative SIC $(62 \%)$ than in those with $\mathrm{OA}(44 \%, \mathrm{p}=0.026)$ (table 1$)$. Of the 71 $(52 \%)$ subjects with negative SIC 37 underwent separate challenges with more than one occupational agent before excluding the diagnosis of OA. Subjects with OA were slightly younger, had a higher level of education and professional qualification, and included a lower proportion of smokers than subjects with negative SIC (table 1). Interestingly, a history of asthma before employment was less prevalent among subjects with work-aggravated asthma symptoms (five of $71,7 \%$ ) than among those with OA (17 of 86, 20\%, $\mathrm{p}=0.022)$. The prevalence of pre-existing asthma was similar in subjects referred by the WCB for medicolegal purposes (13 of 97, 13\%) and in those who were referred by their attending physician (nine of 60, 15\%). Also, a history of asthma before employment was not affected by the nature of the causative agent. The agent suspected of causing work-related asthma symptoms was a high molecular weight compound in 72 of $135(53 \%)$ subjects with OA and in 10 of 22 $(46 \%)$ subjects with negative SIC.

At initial assessment, there were no significant differences in FEV1 and global asthma-severity score between subjects with OA and those with negative SIC (table 2), although histamine PC20 values were lower in subjects with OA $\left(0.72 \mathrm{mg} \cdot \mathrm{mL}^{-1}(0.09-2.57)\right)$ than in those with negative SIC $\left(1.46 \mathrm{mg} \cdot \mathrm{mL}^{-1}(0.23-5.27)\right)$.

\section{Socioeconomic outcomes}

The impact on employment and income was only slightly different in subjects with OA than in those
Table 1.-Demographic characteristics at initial assessment

\begin{tabular}{|c|c|c|}
\hline & $\begin{array}{l}\text { Occupational } \\
\text { asthma }\end{array}$ & $\begin{array}{l}\text { Subjects with } \\
\text { negative SIC }\end{array}$ \\
\hline Subjects $n$ & 86 & 71 \\
\hline Sex female & $33(38)$ & $25(35)$ \\
\hline Age $\mathrm{yr}^{\#, \oplus}$ & $35(32-47)$ & $46(34-54)$ \\
\hline \multicolumn{3}{|l|}{ Education level ${ }^{+}$} \\
\hline$\leqslant 9$ yrs & $22(26)$ & $25(36)$ \\
\hline $10-12$ yrs & $33(38)$ & $33(47)$ \\
\hline$>12$ yrs & $31(36)$ & $12(17)$ \\
\hline Unskilled labour ${ }^{\S}$ & $31(36)$ & $43(61)$ \\
\hline \multicolumn{3}{|l|}{ Smoking habits $f$} \\
\hline Smokers & $8(9)$ & $13(18)$ \\
\hline Exsmokers & $21(24)$ & $25(35)$ \\
\hline Atopy & $52(60)$ & $38(53)$ \\
\hline Referral by WCB & $51(59)$ & $46(64)$ \\
\hline \multicolumn{3}{|l|}{$\begin{array}{l}\text { Agents suspected of } \\
\text { causing symptoms } n\end{array}$} \\
\hline Latex & 30 & 8 \\
\hline Flour & 14 & 16 \\
\hline Wood dust & 9 & 11 \\
\hline Isocyanates & 7 & 11 \\
\hline Metals, welding & 10 & 1 \\
\hline Paints, resins, glues & 1 & 12 \\
\hline Enzymes & 3 & 2 \\
\hline Aldehydes & 1 & 4 \\
\hline Antibiotics & 1 & 2 \\
\hline Persulphate salts & 3 & 1 \\
\hline Various chemical agents & 6 & 5 \\
\hline $\begin{array}{l}\text { Various animal or } \\
\text { vegetal agents }\end{array}$ & 2 & 0 \\
\hline
\end{tabular}

Data are presented as $n(\%)$ unless otherwise stated. SIC: specific inhalation challenge; WCB: Workers Compensation Board. ${ }^{\#}$ : median (25-75th percentiles); $: \mathrm{p}=0.05 ;{ }^{+}: \mathrm{p}=0.018$; $\S: \mathrm{p}=0.002 ;{ }^{f}: \mathrm{p}=0.038$ comparing subjects with occupational asthma and those with negative SIC.

with negative SIC (table 3). The proportion of those currently working was $54 \%$ in subjects with negative SIC and $62 \%$ in those with OA. Retirement was more frequent in subjects with negative SIC (11 of 71, 15\%) than in those with OA (two of $86,2 \%, p=0.005$ ). Asthma was the self-reported cause of work disruption (i.e. unemployment, chronic sick leave, or retirement) in 27 of $33(82 \%)$ of subjects with OA and in 20 of $33(61 \%, \mathrm{p}=0.057)$ of those with negative SIC. Thirty-eight subjects with negative SIC (54\%) reported asthma-related work disability, as defined by being unemployed or having changed jobs because of asthma symptoms, as compared with 62 subjects $(72 \%)$ in the OA group. Only $5 \%$ of subjects in both groups benefited from a professional rehabilitation programme. A similar proportion $(\sim 30 \%)$ of subjects in both groups remained exposed to the agent(s) causing asthma symptoms. However, a higher proportion of subjects with negative SIC $(20 \%)$ than with OA $(7 \%)$ were exposed to unchanged levels of the causal agent(s), whereas the level of exposure was reduced in $26 \%$ of those with OA and in only $8 \%$ of those with negative SIC. The results of the logistic regression analysis exploring the factors that determined employment status at follow-up are presented in table 4 . The risk of being unemployed 
Table 2. - Clinical and functional characteristics at initial assessment

\begin{tabular}{|c|c|c|}
\hline & Occupational asthma & Subjects with negative SIC \\
\hline Subjects $n$ & 86 & 71 \\
\hline Asthma before employment $\mathrm{n}(\%)$ & $17(20)$ & $5(7)$ \\
\hline $\begin{array}{l}\text { Duration of exposure before onset of } \\
\text { work-related asthma symptoms month }\end{array}$ & $82(26-164)$ & $93(20-195)$ \\
\hline Duration of asthma before diagnosis month ${ }^{\#}$ & $46(24-77)$ & $36(19-68)$ \\
\hline Removal from work before SIC & $46(53)$ & $40(56)$ \\
\hline Time lapse from last work exposure to SIC month\# & $0.6(0.1-16.5)$ & $2(0.1-17.0)$ \\
\hline Duration of follow-up month & $40(28-67)$ & $47(29-66)$ \\
\hline Asthma-severity score & $8(5-9)$ & $7(5-8)$ \\
\hline FEV1 \% pred $\#$ & $93(83-102)$ & $93(81-100)$ \\
\hline FEV $1<80 \%$ pred & $12(14)$ & $17(24)$ \\
\hline $\mathrm{FEV} 1 / \mathrm{FVC} \%$ & $78(71-81)$ & $75(69-81)$ \\
\hline Histamine PC $20, \mathrm{mg} \cdot \mathrm{mL}^{-1 \#,+}$ & $0.72(0.09-2.57)$ & $1.46(0.23-5.27)$ \\
\hline$\geqslant 16 \mathrm{mg} \cdot \mathrm{mL}^{-1}$ & $6(7)$ & $5(7)$ \\
\hline $2-16 \mathrm{mg} \cdot \mathrm{mL}^{-1}$ & $19(22)$ & $23(32)$ \\
\hline $0.25-2 \mathrm{mg} \cdot \mathrm{mL}^{-1}$ & $32(37)$ & $24(34)$ \\
\hline$<0.25 \mathrm{mg} \cdot \mathrm{mL}^{-1}$ & $29(34)$ & $19(27)$ \\
\hline
\end{tabular}

Data are presented as $\mathrm{n}(\%)$ or $\mathrm{n}$ (range). SIC: specific inhalation challenge; FEV1: forced expiratory volume in one second; FVC: forced vital capacity; PC20: provocation concentration causing a $20 \%$ fall in FEV $1 .{ }^{\#}$ : median $\left(25\right.$ th- 75 th percentiles); ${ }^{\circ}$ : $\mathrm{p}=0.022 ;^{+}: \mathrm{p}=0.021$ comparing subjects with occupational asthma and those with negative SIC.

was significantly associated with an older age and a lower level of education.

A similar proportion of subjects with OA $(62 \%)$ and with negative SIC $(59 \%)$ reported that they suffered a reduction in income (table 3 ). There was a good correlation between perceived and actual loss of earnings $(\mathrm{rho}=0.87, \mathrm{p}<0.001)$. The median $(25-75$ th percentile) actual loss as a percentage of initial income was $22 \%(0-44)$ in the OA group and $23 \%(0-41)$ in the group with negative SIC. The magnitude of perceived loss of earnings correlated inversely with the level of exposure to the causal agent at follow-up (rho=-0.48, $\mathrm{p}<0.001)$. A loss of income was reported by four of $20(20 \%)$ subjects with persistent exposure,

Table 3. -Employment, exposure, and income status at follow-up

\begin{tabular}{lcc} 
& Occupational asthma & Subjects with negative SIC \\
\hline Subjects n & 86 & 71 \\
Asthma-related work disability,f & $62(72)$ & $38(54)$ \\
Working status & $53(62)$ & $38(54)$ \\
Currently working & $18(21)$ & $17(24)$ \\
$\quad$ Same job, same employer & $4(5)$ & $3(4)$ \\
Same job, different employer & $13(15)$ & $7(10)$ \\
Different job, same employer & $18(21)$ & $11(15)$ \\
Different job, different employer & $33(38)$ & $33(46)$ \\
Not working & $22(26)$ & $15(21)$ \\
Unemployment & $9(10)$ & $7(10)$ \\
Chronic sick leave & $2(2)$ & $11(15)^{\S}$ \\
Retirement & $58(67)$ & $51(72)$ \\
Exposure to the causal agent $\# \#$ & $6(8)$ \\
Cessation of exposure & $22(26)$ & $14(20)$ \\
Reduction of exposure & $6(7)$ & $26(37)$ \\
Persistence of exposure & & $6(8)$ \\
Income status & $31(36)$ & $36(51)$ \\
Perceived change in income & $9(10)$ & $23(0-41)$ \\
$\quad$ No reduction & $45(52)$ & $55(78)$ \\
Slight reduction & $22(0-44)$ & $2(3)$ \\
Major reduction & $83(96)$ & $1 / 2$ \\
Actual reduction in income \% from initial & $75(92)$ &
\end{tabular}

Data are presented as n (\%) unless otherwise stated. SIC: specific inhalation challenge. ${ }^{\#}$ : defined as ever having changed jobs or left work due to asthma; ${ }^{\uparrow}$ median $\left(25\right.$ th -75 th percentiles). ${ }^{+}$: number of subjects who reported a loss of income and who answered this question; ${ }^{\S}: \mathrm{p}=0.005$ when comparing the proportion of retired workers in both groups; ${ }^{f}: \mathrm{p}=0.016 ;{ }^{\# \#}: \mathrm{p}=0.003$; ***: $\mathrm{p}<0.001$ comparing subjects with occupational asthma and those with negative SIC. 
Table 4. - Odds ratios (OR) for being employed at follow-up

\begin{tabular}{lcc}
\hline Variable & OR & $95 \%$ CI \\
\hline $\begin{array}{l}\text { Age yrs*** } \\
\text { Level of education }\end{array}$ & 0.91 & $0.87-0.95$ \\
$\quad \leqslant 9$ yrs, 10-12 yrs, >12 yrs & 2.21 & $1.25-3.89$ \\
$\begin{array}{l}\text { SIC result } \\
\quad \text { positive versus negative }\end{array}$ & 0.62 & $0.27-1.45$ \\
$\begin{array}{l}\text { Asthma-severity score 28-point scale } \\
\text { Log PC20 Log unit }\end{array}$ & 0.91 & $0.78-1.06$ \\
$\begin{array}{l}\text { Time elapsed since onset of } \\
\quad \text { work-related symptoms months }\end{array}$ & 0.91 & $0.75-1.12$ \\
$\begin{array}{l}\text { Company size } \\
\quad \text { number of workers } \leqslant 10,\end{array}$ & 0.99 & $0.99-1.02$ \\
$\quad 10-100,>100$ & & $0.60-1.62$ \\
\hline
\end{tabular}

CI: confidence interval; SIC: specific inhalation challenge; PC20: provocation concentration causing a $20 \%$ fall in forced expiratory volume in one second. $* * *: \mathrm{p}<0.001$; ${ }^{\#}$ : $\mathrm{p}=0.006$.

nine of $28(32 \%)$ subjects with reduced exposure, and 83 of $107(78 \%)$ subjects who were no longer exposed. Of 82 subjects with $\mathrm{OA}$ who had filed a claim for compensation to the WBC, $75(91 \%)$ had been compensated at the time of follow-up. A lower proportion of subjects with negative SIC $(78 \%)$ had attempted to claim compensation and of these, only two received compensation. Among subjects with $\mathrm{OA}$, the loss of earnings was offset by the WCB permanent disability indemnity in only 10 of $45(22 \%)$ subjects who reported an income loss for whom this information was available.

\section{Discussion}

\section{Limitations of the study}

Potential limitations of this study should be carefully considered, since the validity of the inferences that can be drawn from the findings depends to a great extent on the method used to identify the disease of interest and on the populations being studied. Much controversy arises from the absence of objective criteria for defining work-related asthma in the absence of immunological OA or reactive airwaysdysfunction syndrome [3]. Terms such as exacerbation, aggravation, and worsening of asthma at work refer to self-reported symptoms but not to physiological indices of asthma [2, 3, 5]. A group of subjects who demonstrated a negative SIC response were investigated as a proxy for those who experienced worsening of asthma symptoms at work without objective evidence of work-related worsening of asthma disease. Subjects with a clinical history consistent with reactive airways-dysfunction syndrome or acute irritant-induced asthma were excluded from this study. Accordingly, the group with negative SIC included subjects with pre-existing or coincidental asthma whose symptoms were temporally related to workplace exposure, although the underlying pathophysiological mechanisms were unknown.

This study group could also include some subjects with false-negative SICs, although this is unlikely to have occurred. A long interval of time between the investigation and last work exposure could lead to false-negative results [3]. Although approximately half of the subjects with positive and negative SIC had been removed from their jobs at the time of the tests, the duration of removal did not differ between the two groups. The subjects were challenged with the suspected agent(s) for prolonged periods (at least $4 \mathrm{~h}$ ) before excluding OA. In addition, subjects who demonstrated a significant and reproducible decrease in postchallenge histamine PC20 value were considered as having $\mathrm{OA}$, even in the absence of an asthmatic reaction $[18,21]$. Some subjects may not have been challenged with the agent that actually caused asthma at work. However, SICs were carried out in a realistic way, aimed at reproducing the workplace exposure. Approximately half of the subjects were challenged with multiple agents to which they were exposed at work. Also, subjects with indeterminate results of SIC and those for whom the SIC in the laboratory could not adequately reproduce the mode of exposure at work were excluded from the study.

This study assessed subjects who had been referred to a specialized centre by their attending physicians $(38 \%)$, including general practitioners, chest physicians and occupational physicians, or by the WCB $(62 \%)$. The cohort in this study was not formed from a selection bias towards more complex cases. Frenchspeaking workers who filed a claim for compensation have been systematically referred to the authors' centre for SIC since 1993, although SICs with flour were requested only when there was discordance between the results of the other diagnostic procedures. Therefore, OA caused by flour may be underrepresented in the study population. Nevertheless, it is likely that the subjects represented only a subset of those who experience work-related asthma, since their symptoms were severe enough for them to seek specialized medical advice or claim compensation. Conversley, severe asthmatics were probably underrepresented in this study population, as SIC are contraindicated in subjects with severe airway obstruction. For instance, during the study period (1994-1999), SIC could not be carried out in 10 subjects referred to the authors' centre because their asthma was unstable despite appropriate treatment.

\section{Findings}

The rates of unemployment and income loss in subjects with negative SIC $(46 \%$ and 59\%, respectively) did not differ significantly from those observed in subjects with OA in this study $(38 \%$ and $62 \%)$ or in other European studies [8, 9, 11-14]. However, determining the specific effects of work-related asthma requires a control group of subjects experiencing asthma of similar severity without symptoms at work, since there is some suggestion that asthma per se is associated with a negative impact on employment and job effectiveness [19, 22, 23]. Axon et al. [24] found that subjects with occupational asthma were more likely to be unemployed than subjects with nonoccupational asthma $(3 \%)$, although the subjects were not 
matched for the severity of asthma. The findings in this study in subjects with negative SIC were similar to those reported in the only study that assessed the outcome of work-exacerbated asthma [11]. In the study by CANNON et al. [11], subjects investigated for possible OA were considered as having workexacerbated asthma, OA, or asthma unrelated to work based on the clinician's interpretation of a combination of diagnostic procedures, including the clinical history, measurement of specific antibodies, peak-flow recordings and SIC, although the criteria used for diagnostic categorization were not precisely defined. The rate of unemployment was not different in workexacerbated asthma $(31 \%)$, OA $(39 \%)$, or asthma unrelated to work $(32 \%)$, although a reduction of income was more frequently reported by subjects with work-exacerbated asthma $(65 \%)$ and OA $(62 \%)$ than by those with asthma unrelated to work $(38 \%)$. The effects of asthma on work disability defined by breathing-related job changes have been investigated in a population-based study of Swedish adults [19]. Respiratory work disability was found in $2.3 \%$ of subjects without asthma. $13 \%$ of subjects with selfreported asthma, and $22 \%$ of asthmatics with documented airway hyperresponsiveness. Using the same definition, $54 \%$ of subjects with work-aggravated asthma symptoms and $72 \%$ of subjects with OA in this study should be considered as having asthmarelated work disability.

In this study population, logistic regression analysis showed that old age and low education level were the most significant predictors of unemployment. Previous studies of subjects with OA identified various sociodemographic factors that adversely affected the employment status, including manual socioeconomic groups [9], low level of education [13], old age [10], young age [13] and small family with a low number of dependants [10], and small-sized company [13], while the severity of asthma was not an important determinant of the working status.

To conclude, there is controversy as to whether a distinction should be made between nonspecific exacerbation of asthma symptoms at the workplace and immunologically-mediated occupational asthma for prevention, management, and medicolegal purposes $[3,5,25]$. This study shows that, even in the absence of demonstrable occupational asthma, workrelated asthma symptoms are associated with a considerable socioeconomic impact. The environmental and host factors that determine worsening of asthma. symptoms at work should be further investigated in order to improve the medical management of this common condition and to avoid unwarranted professional and financial consequences.

\section{References}

1. Blanc PD, Toren K. How much adult asthma can be attributed to occupational factors? Am J Med 1999; 107: 580-587.

2. Tarlo SM, Leung K, Broder I, Silverman F, Holness DL. Asthmatic subjects symptomatically worse at work: prevalence and characterization among a general asthma clinic population. Chest 2000; 18: 1309-1314.

3. Chan-Yeung M, Brooks S, Alberts W, et al. Assessment of asthma in the workplace. Chest 1995; 108: 1084-1117.

4. Malo JL, Ghezzo H, L'Archeveque J, Lagier F, Perrin $\mathrm{B}$, Cartier A. Is the clinical history a satisfactory means of diagnosing occupational asthma? Am Rev Respir Dis 1991; 143: 528-532.

5. Malo JL, Chan-Yeung M. Comment on the editorial "occupational asthma: prevention by definition". $\mathrm{Am}$ J Ind Med 1999; 35: 207-208.

6. Malo JL, Ghezzo H, L'Archeveque J, Cartier A. Late asthmatic reactions to occupational sensitizing agents: frequency of changes in nonspecific bronchial responsiveness and of response to inhaled beta $2_{2}^{-}$ adrenergic agent. J Allergy Clin Immunol 1990; 85: 834-842.

7. Lemiere C, Chaboilliez S, Trudeau C, et al. Characterization of airway inflammation after repeated exposures to occupational agents. $J$ Allergy Clin Immunol 2000; 106: 1163-1170.

8. Venables KM, Davison AG, Newman Taylor AJ. Consequences of occupational asthma. Respir Med 1989; 83: 437-440.

9. Gannon PF, Weir DC, Robertson AS, Burge PS. Health, employment, and financial outcomes in workers with occupational asthma. $\mathrm{Br} J$ Ind $\mathrm{Med}$ 1993; 50: 491-496.

10. Marabini A, Dimich-Ward H, Kwan, Kennedy SM, Waxler-Morrison N, Chan Yeung M. Clinical and socioeconomic features of subjects with red cedar asthma. A follow-up study. Chest 1993; 104: 821-824.

11. Cannon J, Cullinan P, Newman Taylor A. Consequences of occupational asthma. BMJ 1995; 311: 602-603.

12. Dewitte JD, Chan-Yeung M, Malo JL. Medicolegal and compensation aspects of occupational asthma. Eur Respir J 1994; 7: 969-980.

13. Ameille J, Pairon JC, Bayeux MC, et al. Consequences of occupational asthma on employment and financial status: a follow-up study. Eur Respir J 1997; 10: 55-58.

14. Moscato G, Dellabianca A, Perfetti L, et al. Occupational asthma: a longitudinal study on the clinical and socioeconomic outcome after diagnosis. Chest 1999; 115: 249-256.

15. American Thoracic Society. Standardization of spirometry. 1994 update. Am J Respir Crit Care Med 1995; 152: $1107-1136$.

16. European Community for Coal and Steel. Standardization of lung function tests. Bull Eur Physiopathol Respir 1983; 19: Suppl. 5, 45-51.

17. Cockcroft DW, Killian DN, Mellon JJ, Hargreave FE. Bronchial reactivity to inhaled histamine: a method and clinical survey. Clin Allergy 1977; 7: 235-243.

18. Vandenplas O, Delwiche JP, Jamart J, Van de Weyer $\mathrm{R}$. Increase in non-specific bronchial hyperresponsiveness as an early marker of bronchial response to occupational agents during specific inhalation challenges. Thorax 1996; 51: 472-478.

19. Blanc PD, Ellbjar S, Janson C, et al. Asthma-related work disability in Sweden. The impact of workplace exposures. Am J Respir Crit Care Med 1999; 160: 2028-2033.

20. Blanc PD, Jones M, Besson C, Katz P, Yelin E. Work 
disability among adults with asthma. Chest 1993; 104: 1371-1377.

21. Lemiere C, Cartier A, Dolovich J, et al. Outcome of specific bronchial responsiveness to occupational agents after removal from exposure. Am J Respir Crit Care Med 1996; 154: 329-333.

22. Sibbald B, Anderson HR, McGuigan S. Asthma and employment in young adults. Thorax 1992; 47: 19-24.

23. Blanc PD, Trupin L, Eisner M, et al. The work impact of asthma and rhinitis: findings from a populationbased survey. J Clin Epidemiol 2001; 54: 610-618.

24. Axon EJ, Beach JR, Burge PS. A comparison of some of the characteristics of patients with some of the characteristics of patients with occupational and nonoccupational asthma. Occup Med (Lond) 1995; 45: 109-111.

25. Wagner GR, Wegman DH. Occupational asthma: prevention by definition. Am J Ind Med 1998; 33: 427-429. 